\title{
HISTÓRIA E TRANSFORMAÇÃO NO DIREITO INTERNACIONAL NA AMÉRICA LATINA: A VIRADA DECOLONIAL E A VIRADA HISTORIOGRÁFICA
}

\author{
Larissa Ramina* \\ Laura Maeda Nunes**
}

\section{RESUMO}

Este artigo pretende analisar alterações recentes na doutrina do direito internacional na América Latina. A partir de revisão bibliográfica do direito internacional e dos estudos póscoloniais, almeja-se contrastar enfoques teórico-metodológicos tradicionais e críticos, perquirindo o que esteja por detrás dessa mudança de abordagem. A "virada decolonial" tem relevância na investigação, dedicando-se aos impactos do colonialismo nos povos latinos. A "virada historiográfica" é igualmente importante no crescente interesse pela historiografia da disciplina na região. A aproximação entre referidas "viradas" permite um olhar historiográfico para o direito internacional na América Latina, revisando a história "oficial" e liberando-o de vínculos com o colonialismo.

Palavras-chave: virada decolonial; virada historiográfica; história do direito internacional; direito internacional; América Latina.

\section{HISTORY AND TRANSFORMATION IN INTERNATIONAL LAW IN LATIN AMERICA: THE DECOLONIAL TURN AND THE HISTORIOGRAPHIC TURN}

\begin{abstract}
This article aims to analyze recent changes in the doctrine of international law in Latin America. Based on a bibliographic review of international law and post-colonial studies, the purpose is contrast traditional and critical theoretical-methodological approaches, investigating what is behind this change. The "decolonial turn" has relevance, focusing on the impacts of colonialism on Latin people. The "historiographical turn" is equally important in the growing interest in the discipline's historiography in the region. The approximation between the referred "turns" allows a historiographic look at international law in Latin America, reviewing the "official" history and releasing it from ties with colonialism.
\end{abstract}

Keywords: decolonial turn; historiographical turn; history of international law; international law; Latin America.

\section{Introdução}

\footnotetext{
Professora de direito internacional da Universidade Federal do Paraná - UFPR, doutora em direito internacional pela Universidade de São Paulo - USP e pós-doutora em direito internacional pela Université de Paris Quest - Nanterre La Défense. Endereço postal: Praça Santos Andrade, n. 50, Curitiba, Paraná. Endereço eletrônico: raminalarissa@gmail.com.

** Mestranda e graduada em direito pela Universidade Federal do Paraná - UFPR, pesquisadora do Grupo de Investigação INTER - Enfoques Críticos do Direito Internacional. Advogada. Endereço postal: R. Comendador Araujo, 692, Curitiba, Paraná. Endereço eletrônico: lauramaedanunes@ gmail.com.
} 
A proposta do presente estudo é a de analisar as recentes mudanças na doutrina do direito internacional no âmbito latino-americano. Pretende-se, mais especificamente, aguçar os contrates entre enfoques teórico-metodológicos tradicionais e críticos e, a partir disso, questionar quais são os fatos que estão por detrás dessa mudança de enfoque na doutrina dessa disciplina na região.

O que se nomeia "virada decolonial" tem relevância nessa investigação, na medida em que guarda estrita relação com a contribuição dos estudos pós-coloniais dentro do pensamento jurídico crítico, que se debruçam sobre os legados do colonialismo e de seus impactos sociais nos países e nos povos latino-americanos.

Essas teorias pós-coloniais possibilitam, também, um olhar historiográfico para o direito internacional, a fim de desnaturalizar e desconstruir categorias, conceitos e narrativas, resistindo ao esquecimento da história, ou das muitas histórias, que levaram aos resultados da colonização. O crescimento do interesse pela historiografia do direito internacional na região latino-americana guarda também relação com o que se denomina "virada historiográfica" na disciplina.

Um exemplo de enfoque crítico na disciplina são as TWAIL, “Abordagens do Terceiro Mundo ao Direito Internacional", que têm contribuído ao estudo jurídico internacional durante as últimas décadas. As TWAIL se propõem a analisar a história e a evolução do direito internacional desde a perspectiva da experiência vivida pelos povos do chamado "terceiro mundo", categoria que está sendo resgatada doutrinariamente.

A aproximação da virada historiográfica com a virada decolonial empresta novo semblante ao direito internacional na América Latina, representando a ambição crescente na região de se revisar a história "oficial" e liberar o direito internacional de todos os vínculos com o colonialismo e pensar a partir de categorias negadas, assim como sobre as contradições nas quais o sistema jurídico contemporâneo se funda. Além disso, as abordagens terceiromundistas permitem concluir que os juristas não estudam o direito internacional simplesmente lançando mão do passado como parcela cronológica e introdutória da disciplina, mas o utilizando como meio para se ligar de alguma forma ao presente, inclusive mediante conceitos que se adaptam ao longo do tempo e do espaço, assim como permitem verificar como o passado pode ser uma fonte de obrigações do presente, podendo, ainda, auxiliar na construção de uma outra historiografia do direito internacional. 
A presente pesquisa, metodologicamente, se constrói pela revisão bibliográfica de expoentes autores críticos do direito internacional e dos estudos pós-coloniais latinoamericanos. Para além desta breve introdução, o desenvolvimento do trabalho se estrutura em três seções e em considerações finais. A primeira seção tem por finalidade contrastar abordagens teórico-metodológicas a respeito da história no direito internacional, buscando evidenciar seus diferentes propósitos, o que se faz essencialmente a partir de aportes indicados por George Rodrigo Bandeira Galindo, Professor de direito internacional da Universidade de Brasília. A segunda seção se dedicará ao debate pós-colonial, especialmente pelo viés das contribuições latino-americanas, e a terceira seção, a seu turno, buscará adentrar nos impactos das contribuições pós-coloniais na disciplina do direito internacional, com ênfase nas abordagens terceiro-mundistas, almejando-se provocar reflexões acerca do direito internacional contemporâneo em uma perspectiva histórica crítica.

\section{Contrastes entre abordagens teórico-metodológicas da história no direito internacional}

No âmbito do direito internacional, existem múltiplas vertentes teóricas e metodológicas que possibilitam seu estudo por diferentes vieses a partir da história, que podem tanto reforçar leituras tradicionais como podem, também, problematizá-las. GORDON (1996), importante historiador do direito americano, dividiu didaticamente em três as atitudes do jurista em relação ao olhar do passado, sendo elas a estática, a dinâmica e a crítica.

A posição estática assume uma norma ou prática jurídica como detentora de significado fixo imutável, estabelecido por seus usos no passado, cabendo ao jurista apenas angariar do passado esse significado. Essa postura se aproxima de pressupostos positivistas, na medida em que o sujeito intérprete é passivo na análise do objeto (passado), sendo que o conhecimento se limita a uma representação espelhada da verdade real, que reflete fielmente o que o objeto é (FONSECA, 2011). Para essa vertente, o papel do historiador seria a busca de uma verdade no passado, por meio da coleta do máximo de material possível nos arquivos históricos, com a finalidade de comprovar que algo de fato aconteceu ou que sempre foi assim.

Nessa perspectiva, no que toca ao direito internacional, há quem defenda que a disciplina tem e deve continuar a ter as mesmas funções desde o seu surgimento, qual seja, promover a coexistência e objetivos comuns entre Estados. George Galindo identifica o internacionalista francês Prosper Weil como um dos defensores dessa linha, em razão de ter 
publicado na American Journal of International Law, em 1983, artigo intitulado "Towards relative normativity in international law?", no qual conclamava os juristas da área internacional a lutarem contrariamente ao que nomeou "relativização normativa" no direito internacional. À época, conceitos como soft law, jus cogens e crimes internacionais ganhavam relevo e, para Weil, estavam a subverter a estrutura que o direito internacional possui desde a sua criação: o soft law retiraria do direito internacional sua típica natureza normativa, ao passo que jus cogens e crimes internacionais criariam uma hierarquização imprópria de normas, posicionando umas como sendo mais importante que outras (GALINDO, 2015). A partir desse viés, não haveria sentido falar em um direito internacional clássico e em um direito internacional moderno.

Por outro ângulo, quando o jurista assume uma posição dinâmica em relação à história, seu papel passa a ser o de tornar o futuro melhor do que o passado, quase que em uma missão de progresso, assumindo que a interpretação jurídica varia e, mais do que isso, deve variar com o tempo para se adaptar às mudanças de condições. Muito embora de forma mais tímida se comparada à vertente estática, a abordagem dinâmica também se aproxima de correntes historiográficas dos séculos XVIII e XIX, que acreditavam em um progresso contínuo e linear da espécie humana e das estruturas sociais. Especificamente no campo do direito internacional, George Galindo rememora o popular manual de direito internacional "Curso de Derecho Internacional Público y Organizaciones Internacionales", do espanhol José António Pastor Ridruejo:

\footnotetext{
Uma das teses principais do autor é que o direito internacional clássico e o direito internacional contemporâneo se distinguem por três características básicas. Enquanto o primeiro possuía as características de liberal, descentralizado e oligárquico, o direito internacional contemporâneo seria um ordenamento jurídico de caráter social, institucionalizado e democrático. Embora Pastor Ridruejo reconheça que nem todas as características do direito internacional clássico desapareceram, não são elas mais aspiradas pela comunidade internacional. (GALINDO, 2015, p. 342)
}

Essa postura dinâmica assumida pelo jurista em relação à história, portanto, busca autoridade no passado para sustentar características do presente. Do trecho acima transcrito, por exemplo, pode-se identificar que apenas se afirmam as características de um direito internacional contemporâneo como sendo "social, institucionalizado e democrático" a partir da referência em relação ao passado, de um direito internacional clássico "liberal, 
descentralizado e oligárquico". O presente, assim e nessa perspectiva, se conecta com o passado de modo inseparável, sendo dele resultado.

Comparando-se as posturas estática e dinâmica do jurista sobre o passado, é possível extrair uma importante diferença: a vertente dinâmica utiliza e defende o conhecimento do passado para que o presente e o futuro sejam diferentes dele, ao passo que a vertente estática sustenta que o passado seja conhecido para que o presente e o futuro sigam sendo como ele. Por outro lado, há nítida característica comum entre as duas abordagens, que é a de buscar no passado legitimação para o presente, ainda que lançando mão de meios diferentes, para manutenção ou progresso em relação ao passado. Trazendo o enfoque para o direito internacional, a função de uma abordagem histórica da disciplina, seja assumindo postura estática seja adotando a dinâmica, seria a de legitimar argumento, norma ou proposta sobre a organização jurídica internacional (GALINDO, 2015).

Uma terceira postura possível de ser adotada pelo jurista ao abordar o passado é, como mencionado alhures, a crítica. Para Galindo, é ela a mais adequada quando se vislumbra a função da história do direito internacional como um mecanismo que pode auxiliar a operar mudanças mais profundas no direito internacional em favor dos tradicionalmente excluídos ou marginalizados, lançando mão com mais vigor do aporte histórico de forma interdisciplinar (GALINDO, 2015).

A história não é estática, nem linear, tampouco deve servir de justificação determinante ao presente. Os fatos históricos podem ser, e muitas vezes são escolhidos, sem neutralidade, para se narrar a história sob a perspectiva que se pretende, inclusive sob uma roupagem de neutralidade e de verdade absoluta. O que se deve buscar ao olhar o passado, entretanto, é uma abordagem crítica e reflexiva responsável, consciente das vicissitudes e das contradições próprias de qualquer tempo histórico e do pluralismo de narrativas possíveis em relação a ele (FONSECA, 2011).

A proposta da abordagem crítica do jurista em relação ao passado é muito mais a de buscar descontinuidades discursivas do que continuidades, o que tem levado cada vez mais historiadores críticos do direito internacional a se deparar com uma multiplicidade de narrativas e de significados que convivem em um mesmo tempo histórico. Almeja-se, por essa ótica, questionar e desconstruir a utilização do passado como argumento de autoridade para legitimar argumento no presente. A “instrumentalização" do passado se presta, em uma 
análise crítica, a quebrar tradições ou, ao menos, a reinterpretar a construção dessas mesmas tradições, após revisitar seus fundamentos (GALINDO, 2015).

É essa a abordagem que tem se verificado cada vez mais presente no estudo da história do direito internacional nas últimas décadas, em especial em países fora do centro global que se autoproclama hegemônico. Na seção seguinte, a análise se centrará na investigação de elementos que colaboraram para que essa tendência crítica pudesse ser vislumbrada no horizonte latino-americano, buscando dar ênfase às colaborações dessa região para o debate pós-colonial.

\section{América Latina e a virada decolonial}

É importante que se esclareça, de início, que quando se lança mão da terminologia “pós-colonial" não se está a referir tão somente à ideia cronologicamente restrita ao período histórico seguinte à declarada independência das colônias em relação às metrópoles, mas também ao conjunto de produções teóricas que ganharam evidência a partir dos anos 1980, notadamente análises econômicas, sociológicas e políticas sobre a construção dos novos Estados, as rupturas e as permanências com o sistema colonial e as alianças regionais (SANTOS, 2003).

O pós-colonialismo, nas palavras de Leela Gandhi, pode ser entendido como uma resistência teórica a uma "amnésia mistificadora" ("mystifying amnesia") das consequências coloniais, que, adotando uma postura crítica, dedica-se a revisitar e a questionar o passado colonial (GANDHI, 1998, p. 4).

Nesse exercício histórico, LANDER (2005) afirma que, desde a invasão da América, deu-se início a um processo civilizatório no qual a sociedade europeia, ancorada em discursos de evangelização, estabeleceu-se como centro do que veio a ser denominado mundo modernocolonial.

O processo histórico que culminou na chamada modernidade produziu, concomitantemente, colonialidade, estabelecendo um padrão hierárquico de poder e de saber que mantém a dominação dos povos do Sul, tanto no âmbito ideológico-discursivo quanto no plano das relações intersubjetivas (QUIJANO, 2005).

Para DUSSEL (1993), esse processo colonizador acarretou o "encobrimento do outro", gerando supressão e dominação das culturas e dos povos não-europeus, que se tornaram objeto de constante discriminação e de violações à sua integridade, por meio da 
aculturação e do genocídio dos povos nativos, assim como da escravização de povos africanos.

A dominação europeia, porém, não se limitou apenas a interferir na integridade e na igualdade dos povos do Sul global, mas transcendeu e conformou uma racionalidade hegemônica, a que MIGNOLO (2003) nomeia "discurso sobrepujante do ocidentalismo", impondo uma cosmovisão europeia como sendo universal (QUIJANO, 1992).

O capitalismo e os valores liberais-individuais expandiram-se em nível mundial, de modo que as definições jurídicas e doutrinárias europeias passaram paulatinamente a ser implementadas como único conhecimento válido, científico e útil, reprimindo e relegando à marginalidade acadêmica e política qualquer outro produto intelectual que dele diferisse (SANTOS, 2007).

As abordagens pós-coloniais, portanto, colocam como central a necessidade de desestabilizar os discursos dominantes da produção intelectual europeia, problematizando o modo por meio do qual se entende o mundo. Além disso, entendem que a denominação de parcela considerável do planeta como sendo "terceiro mundo" ou "países subsenvolvidos" não é acidental ou inocente, mas um meio de exercer poder. O pós-colonialismo, ademais, procura reescrever a história, recuperando vozes que historicamente foram silenciadas, somando-se a vozes contemporâneas marginalizadas, também com a finalidade de reconstruir a produção de conhecimento (MCEWAN, 2008, p. 125, apud MANTELLI e ALMEIDA, 2019).

A aproximação de teóricos latino-americanos com as abordagens pós-coloniais se dá mais fortemente na década de 1990, no âmbito das ciências sociais, com o Grupo LatinoAmericano dos Estudos Subalternos, que se dedicava a enfatizar categorias políticas, como classe, gênero e, também, nação. Pouco tempo depois de seu surgimento, referido Grupo passou a engrossar vozes críticas aos próprios projetos pós-coloniais estabelecidos até então, passando a denunciar imperialismos internamente, posto que os estudos que não haviam rompido adequadamente com autores eurocêntricos (BALLESTRIN, 2013).

Verificou-se, assim, a necessidade de as abordagens pós-coloniais na América Latina serem mais específicas e tecidas a partir da peculiar realidade experimentada pela região.

A partir do final dos anos 1990, após a realização de encontros no continente, formou-se o Grupo Modernidade/Colonialidade, que passou a se autodenominar representante do pensamento decolonial. A pretensão dos estudos decoloniais, portanto, os faz diferenciar em relação aos estudos pós-coloniais na medida em que almejam certa desobediência 
epistêmica em relação ao saber europeu, ainda que em sua vertente mais crítica. Exatamente essa especificidade é que qualifica a expressão "virada decolonial” (BALLESTRIN, 2013).

O ponto fulcral que distingue pós-colonialismo de decolonialismo é, assim, não apenas a percepção crítica sobre o passado, como também a não reprodução da história de maneira fragmentada e subordinada ao eurocentrismo, dado que, em última análise, caso assim não fosse, acabaria por se reproduzir algo semelhante ao que as elites criolas fizeram nos processos de independência, recriando formas de colonização (RIVEIRA, 2010).

Para ilustrar a atitude de desobediência epistêmica a que se fez referência, Ballestrin, na busca por revisitar a historiografia acadêmica, aduz que:

\footnotetext{
Seria possível, portanto, considerar Qama Pomam de Ayala - do vice-reinado peruano que enviou ao rei Felipe III em 1616 sua Nueva crónica y buen gobierno - e Otabbah Cugoano - um escravo liberto que publicou em Londres, em 1787, Thoughts and sentiments on the evil of slavery - como os primeiros autores de tratados políticos decoloniais, que não usufruem o mesmo prestígio daqueles escritos por Hobbes, Locke ou Rousseau. (BALLESTRIN, 2013, p. 105).
}

Uma das figuras centrais do pensamento decolonial latino-americano, o professor argentino Walter Mignolo, sustenta que as reflexões do teórico peruano Aníbal Quijano são as que enfrentam as peculiaridades da América Latina com maior radicalidade, tendo em vista que, para além da revisão crítica do passado, vislumbram a necessidade de construir outros mundos possíveis, e não apenas construir narrativas que caibam dentro desse mundo. Quijano defende que a heterogeneidade histórico-cultural, a co-presença de fragmentos estruturais de formas de existência social e de várias procedências históricas e geoculturais sejam o principal modo de existência e de movimento de toda a sociedade e, mais do que isso, de toda a história. É o poder e as lutas de poder, nesse contexto, que organizam e hierarquizam a heterogeneidade. Em suas palavras:

Porque é o poder, logo, as lutas de poder e seus mutantes resultados, aquilo que articula formas heterogêneas de existência social, produzidas em tempos históricos diferentes e em espaços distantes, aquilo que as junta e as estrutura em um mesmo mundo, em uma sociedade concreta, finalmente, em padrões de poder historicamente específicos e determinados. (QUIJANO, 2006, p. 14).

O autor destaca, nesse debate, os movimentos político-culturais que resistem em face da colonialidade do poder, especialmente os indígenas e os afro-latino-americanos, que fazem a crítica à racionalidade da modernidade/colonialidade e se colocam como uma racionalidade 
alternativa. Pautam-se em uma ética solidária social, negando legitimidade ao Estado-nação, e demonstrando que a identidade latino-americana é um projeto em construção. São muitas as memórias e muitos os passados, que, portanto, necessitam de uma trajetória de "inevitável destruição da colonialidade do poder, uma maneira muito específica de descolonização e de libertação: a des/colonialidade do poder" (QUIJANO, 2006, p.17).

Cabe pontuar que Quijano dá voz para, e não exatamente cria, a tradição de luta e de resistência de movimentos que, em sua ação política, falam em descolonizar. A inequívoca contribuição de Aníbal Quijano é a de assumir a perspectiva de que não há um tempo ou uma história linear, mas uma verdadeira espiralidade da história latino-americana (BITTENCOURT e MASO, 2015).

Se a hipótese pretendida para a América Latina é, como propõe Quijano, a de pôr fim ao padrão mundial do poder por meio do protagonismo do povo latino-americano, sua luta deve ser necessariamente anti-imperialista e decolonial. $\mathrm{O}$ primeiro passo para tanto seria o de enxergar que a solução binária de transformação do paradigma europeu (revolução burguesa ou revolução socialista) não se aplica de modo semelhante na América Latina. O capitalismo marginal, periférico, subordinado e dependente de toda a região latino-americana pressupõe a impossibilidade histórica de seu desenvolvimento dentro desse sistema-mundo por meio de uma revolução nos moldes conhecidos até então (QUIJANO, 2005).

A democratização será possível na América Latina se ocorrer orquestradamente, na maioria dos países dessa mesma localização geopolítica, em um mesmo movimento histórico, com a redistribuição radical do poder e uma reorganização entre os povos, em sua vida cotidiana, e do controle sobre todas as condições que oprimem sua existência. Defende Quijano que "é tempo de deixar de ser o que não somos" (QUIJANO, 2005, p. 248) e, mais do que reconcentrar, redistribuir entre os latino-americanos o controle sobre as condições de sua existência social (QUIJANO, 2005).

$\mathrm{O}$ questionamento aos discursos que, articulados pelo poder dos países centrais e autodenominados hegemônicos, predominam nas narrativas históricas tradicionais, e a assunção da existência de uma heterogeneidade de fragmentos e de narrativas que formam os diferentes tempos históricos, atravessam diferentes áreas de conhecimento e contribuem, também, para o pensamento jurídico crítico, que se vê desafiado a revisitar sua historiografia, desnaturalizando conceitos, categorias e narrativas. As abordagens pós e decoloniais na área jurídica têm sido utilizadas em disciplinas diversas, como, por exemplo, para problematizar 
institutos do direito penal, para debater questões que envolvem os povos indígenas e outras comunidades tradicionais, bem assim na pauta de um novo constitucionalismo latinoamericano.

No direito internacional, da mesma maneira, referidas abordagens vêm ganhando a dedicação de juristas que adotam postura crítica em relação à disciplina, e será essa a reflexão proposta na próxima seção.

\section{Direito internacional e a virada historiográfica}

O processo histórico que culminou na modernidade e que produziu consigo a colonialidade e a dominação dos povos do chamado sul global, conformando uma racionalidade tida por hegemônica, conforme delineado na seção anterior, fez com que experiências, identidades e narrativas históricas dos povos não europeus fossem suprimidos, de modo que a única narrativa histórica admitida sobre esses povos se restringe a narrar o seu progresso em relação aos padrões europeus de sociedade.

Foi também assim que o direito internacional se revestiu de uma aura de benevolência e de progresso, adquirindo um status praticamente inquestionável de universalidade, racionalidade e virtude, omitindo as violentas práticas coloniais e neocoloniais perpetradas pelos estados e corporações europeus contra os povos não europeus ao longo da história (KOSKENNIEMI, 2011).

Após a onda de descolonização dos anos 1950 e 1960, estudiosos dos países do "terceiro mundo" deram início a estudos críticos em relação ao passado do direito internacional, identificando sua relação com o colonialismo e com o imperialismo. Quando se percebeu que o fim do colonialismo formal não significou uma ruptura, de fato, com o imperialismo, ocorreu um progressivo desencantamento com as promessas emancipatórias do direito internacional. Nesse contexto, e também devido aos efeitos da globalização neoliberal nas realidades dos países em desenvolvimento, o interesse pela questão histórica crítica cresceu na academia do direito internacional (KOSKENNIEMI, 2013).

\footnotetext{
${ }^{1}$ Embora essa expressão traga consigo uma ideia de homogeneidade do Sul global, desconsiderando diferenças em termos de desenvolvimento entre os Estados dessa região, assim como obscureça que nos países de "primeiro mundo" também existem segmentos populacionais que sofrem privações tão ou mais graves quanto populações do Sul, autores ligados às TWAIL têm insistido no uso do termo. Considera-se, em apertada síntese, ser vocábulo essencial para organizar e resistir coletivamente a políticas hegemônicas. Ver CHIMNI, B.S. Third World Approaches to International Law: a manifesto. International Community Law Review. London: The Hague, vol. 8, n. 1, 2006. p. 4-5.
} 
No Brasil, o esforço de estimular as abordagens terceiro-mundistas no direito internacional pode ser creditado, em especial, a George Galindo, segundo quem o marco inicial do movimento remete a eventos acadêmicos norte-americanos em 1997 e que tem angariado simpatizantes não apenas no terceiro mundo, mas também entre autores filiados a outras correntes críticas do direito internacional.

Essa "virada historiográfica", portanto, encontrou ressonância em diferentes âmbitos do direito internacional, dando ensejo ao surgimento de movimentos como Critical Legal Studies (CLS), New Approaches to International Law (NAIL), Third World Approaches to International Law (TWAIL) e o materialismo histórico das abordagens marxistas do direito internacional.

Com raízes nesses movimentos, a história crítica do direito internacional vem se consolidando como um campo de estudo que tem como finalidade analisar o passado da disciplina à luz da experiência imperialista e colonial, de modo a reescrever a história da disciplina não mais como um projeto civilizatório ou um instrumento de progresso humanitário, mas como histórias de colonialismo, violência e exploração. O finlandês Martii Koskenniemi é um dos autores de destaque na crítica a narrativas históricas tradicionais, cumprindo também um papel de denúncia em relação ao passado imperialista e ao universalismo eurocêntrico do direito internacional.

Segundo esse autor, as narrativas tradicionais do direito internacional tendem a relacionar a disciplina aos ideais de paz, progresso, benevolência e aos valores de humanismo, razão e cosmopolitismo. Contam a história do direito internacional europeu, a partir de experiências políticas como Vestefália, Viena, Paris e Genebra, por exemplo, como se fosse a história de toda a humanidade. Esse universalismo do direito e dos valores, em suas palavras, "representaram um meio excelente para mascarar o etnocentrismo e o colonialismo ocidental" (KOSKENNIEMI, 2011).

O professor queniano Makau Mutua, também vinculado às correntes críticas da historiografia do direito internacional, em especial às TWAIL, elenca três objetivos políticoacadêmicos dessa corrente. O primeiro deles é a desconstrução de usos do direito internacional que subordinam os não-europeus aos europeus, ou o sul global ao norte global. O segundo é o de propor alternativas jurídicas de governança internacional, e o terceiro o de erradicar o chamado "subdesenvolvimento" do terceiro-mundo. Para ele, o regime do direito internacional consiste em um sistema predatório que legitima, reproduz e dá sustentação à 
subordinação do terceiro-mundo pelo Ocidente e que é necessário, portanto, que a visão crítica do direito internacional assuma a equidade moral das culturas e rejeite importações jurídicas sem os devidos filtros geopolíticos (MUTUA, 2000).

O srilankês Antony Anghie, por sua vez, é um dos internacionalistas críticos que mais se dedica às origens coloniais do direito internacional. Analisando a invisibilidade das realidades coloniais e pós-coloniais na forma tradicional de apresentar a história do direito internacional, sustenta que o processo de expansão imperial é de fundamental importância para compreender a maneira como se formou o direito internacional e, também, para entender o conceito de soberania - o eixo fundacional do direito internacional contemporâneo. O autor, ainda, busca demonstrar como a missão civilizatória que acompanhou o processo imperial clássico não é um simples evento do passado, mas a razão pela qual se forma o projeto de governo e de transformação dos povos europeus desde a colônia até os dias atuais, presente na mecânica das instituições, normas e discursos internacionais. O abismo existente entre os países civilizados/desenvolvidos e os não civilizados/subdesenvolvidos é o fulcro para entender como funciona a ideia da soberania. (ESLAVA, OBREGÓN, URUEÑA, 2016).

Com raízes religiosas, Anghie argumenta que o naturalismo deu ao direito internacional uma ideia de obrigatoriedade moral. Critica a visão de Francisco de Vitoria, que atribuiu "humanidade" aos indígenas, mas os considerava atrasados e passíveis de se submeterem ao direito universal natural. Essa visão negou as diferenças de ser e de agir dos povos indígenas e causou uma guerra que dizimou essa população. Além do naturalismo, o positivismo também é visto por Anghie como central no sistema imperialista, ao utilizar doutrinas formais que passaram a impor critérios raciais e culturais para determinar se um estado era soberano ou não, e atrasado ou não em termos econômicos. $\mathrm{O}$ fim do colonialismo do século XX não significou o fim das relações coloniais: o velho colonialismo foi substituído por um neocolonialismo, caracterizado pela dependência econômica nas relações centroperiferia (ESLAVA, OBREGÓN, URUEÑA, 2016).

As relações de poder e subordinação econômica foram sendo naturalizadas e aceitas sob o pretexto de busca por uma "segurança global", definida pelos países mais poderosos. A conclusão a que Anghie chega é que o direito internacional é utilizado como instrumento de políticas imperialistas. Ressalta, por outro lado, que essas políticas sempre foram e devem seguir sendo contestadas pelos países do terceiro-mundo. O caminho seria, então, entender a lógica imperial do direito internacional, para ser possível oposição e prevenção em relação a 
elas, possibilitando, assim, um mundo verdadeiramente justo (ESLAVA, OBREGÓN, URUEÑA, 2016).

Uma abordagem materialista da história do direito internacional, na qual é destaque CHIMNI, indica uma interrelação necessária entre os padrões históricos que estruturam a economia mundial - como a divisão internacional do trabalho e a extração de mais-valia -, e as formas institucionais correspondentes da ordem internacional - o direito internacional. Nessa perspectiva, a ordem legal internacional funciona como espécie de superestrutura do sistema econômico mundial, de modo que as relações capitalistas hegemônicas influenciam na atividade da disciplina, que acaba por legitimar o regime de acumulação capitalista em nível global. Essa correspondência de influências entre as fases do capitalismo histórico e a ordem legal é, para o autor indiano, a característica fundamental da relação entre capitalismo, imperialismo e direito internacional (CHIMNI, 1999, 2004).

Ainda, há também contribuições teóricas que aproximam o pós-colonialismo com os direitos humanos no âmbito do direito internacional, linha da qual é destaque o indiano Balakrishan Rajagopal. Para referido teórico, os direitos humanos têm forte característica eurocêntrica, posto que não apenas têm pretensões universalizantes a partir de conceitos ocidentais impostos ao resto do mundo, bem assim porque consolidado por quem possuía a legitimidade epistêmica para elaborar conhecimento válido, sendo produto discursivo da colonialidade (RAJAGOPAL, 2003).

Conforme se evidencia dos autores destacados, as correntes histórico-críticas do direito internacional têm destacado espaço na Ásia e na África, tendo ainda poucos, porém imprescindíveis, teóricos no contexto latino-americano (GATHII, 2019).

Ainda assim, no âmbito da América Latina, a construção teórica de um olhar que se pretende contra-hegemônico e decolonial vem ganhando corpo desde as últimas décadas, notadamente desde os anos 1990 como mencionado alhures, sugerindo a leitura desta região como um dos berços mais importantes do direito internacional na passagem da fase imperial para a moderna. Importa mencionar, por outro lado, que o discurso de "contribuição latinoamericana ao direito internacional" é mais antigo, e parte dos processos de independência e de seu rechaço ao imperialismo.

Nessa perspectiva, alguns internacionalistas da região latino-americana enxergam-na como cooperadora do desenvolvimento do direito internacional em diferentes áreas, seja em princípios e doutrinas gerais, seja na criação de conceitos fundamentais ao direito 
internacional comercial e ao direito internacional dos direitos humanos, como, por exemplo, o princípio da autodeterminação dos povos, o uti possidetis iuris (os que ocupam de fato o território possuem direito sobre ele), o princípio da solução pacífica de controvérsias, o de assistência recíproca e defesa coletiva a agressões externas, a proibição do uso da força, o princípio da solidariedade, o asilo diplomático, o princípio da igualdade entre os estados e o da não intervenção - todos eles surgiram como rechaço da América Latina a imposições imperiais. Após a segunda guerra mundial, a América Latina esteve presente em muitos foros e convenções internacionais, ativamente participando de discussões sobre descolonização. $O$ impulso se concretizou com a substituição de importações e com as discussões sobre uma nova ordem econômica internacional, notadamente em 1974, na Assembleia Geral das Nações Unidas (ESLAVA, OBREGÓN, URUEÑA, 2016).

Embora referidas contribuições tenham representado importantes conquistas para a região latino-americana no âmbito do direito internacional, é importante ressaltar que não estão livres das contradições de condenar a ordem prevalecente ao mesmo tempo em que se referendam as condições estruturantes de uma ordem global desvantajosa para os países do Sul global. Na segunda metade do século XX, a América Latina viveu frustrações geradas por esses comportamentos contraditórios e viu o imperialismo progredir. Por um lado, a região gerou novas propostas no direito internacional e sua posição geopolítica dentro do contexto da guerra fria, e a revolução cubana, em particular, permitiu pensar que os países do continente poderiam dar um salto importante em direção ao futuro. O programa "Aliança para o Progresso" promovido pelo presidente Kenedy para acelerar o desenvolvimento econômico e social da América Latina parecia confirmar essa direção. Entretanto, a "nova ordem econômica internacional”, liderada pelos Estados Unidos, apenas confirmou políticas já bem conhecidas. A visão progressista da América Latina por um mundo diferente se chocou com a acumulação da dívida externa e a década perdida de 1980, e o direito internacional desempenhou importante papel nesse cenário.

ESLAVA, OBREGÓN e URUEÑA (2016) consideram as políticas de ajuste estrutural do Fundo Monetário Internacional (FMI) importantes elementos que permitem visualizar como o direito internacional participou das dinâmicas imperiais na América Latina. Para referidos teóricos, o FMI, enquanto aparato de direito internacional resultado dos acordos de Bretton Woods, atua por meio do direito internacional, aplicando conceitos como soberania e consentimento estatal, por exemplo, de modo a perpetuar o aparato de poderes, 
obrigações e direitos que permitem ao FMI atuar com mecanismos de condicionalidade, aplicando medidas de ajuste econômico com viés muito bem definido, defendendo a política econômica neoliberal.

O que se percebe é uma tomada de consciência crítica por parte de acadêmicos latino-americanos a respeito da herança colonial que carregam seus países, assim como a respeito das estruturas arcaicas que os aprisionam e os subjugam nas mãos dos centros do capitalismo mundial. Essa tomada de consciência crítica leva à percepção de que, ao lado da colonialidade do poder, está a colonialidade do saber, que atua tanto em nível epistêmico quanto filosófico e científico. A colonialidade do saber revela que, para além do legado de desigualdades e injustiças sociais profundas do colonialismo e do imperialismo, há um legado epistemológico do eurocentrismo que impede a compreensão do mundo a partir do lócus periférico em contraposição a um suposto centro, e a partir de epistemos que são próprias de países situados fora do eixo do poder que se pretende hegemônico.

A história do direito internacional pode ser interpretada de diversas formas possíveis, e não existe uma forma "correta" para tanto. O que existe é uma escolha de abordagem em relação ao passado e, a depender da postura adotada pelo intérprete, pode-se priorizar alguns elementos na história em detrimento de outros e, assim, dar funções distintas à história do direito internacional, seja para manutenção do status quo, seja para colaborar com uma possível mudança no âmbito da disciplina e suscitar a criatividade dos juristas nas soluções para problemas globais (GALINDO, 2015), o que passa necessariamente pela compreensão da ordem jurídica internacional e das instituições internacionais desde uma perspectiva crítica.

A abordagem crítica da história do direito internacional é conscientemente um ato político. Ou seja, não se trata de uma narrativa neutra em relação ao passado, mas "uma descrição que espera tornar a situação presente mais clara para nós e afiar nossa própria habilidade para agir nos contextos profissionais que nos são abertos" (KOSKENNIEMI, 2001). O futuro, para esta corrente, é garantido apenas pela persistente insatisfação da crítica e pela preocupação com o presente (GALINDO, 2015).

Compreender o passado criticamente e, a partir dele, estabelecer vínculos com o presente é essencial não apenas para identificar e desconstruir o caráter colonial, imperialista e eurocêntrico do direito internacional contemporâneo, como também para construir um futuro alternativo mais justo do ponto de vista da emancipação humana e do fim da exploração do Sul global. Se se pretende conferir à história papel central no direito 
internacional para romper com tradições estabelecidas, indagando seus próprios fundamentos e, por consequência, permitir a construção de diferentes alternativas para uma organização jurídica internacional mais democrática e justa, é preciso adotar também uma postura ética, levando em consideração a necessária prestação de contas para com as gerações passadas (GALINDO, 2015).

O capitalismo pós-guerras não mais precisa se legitimar e se relegitimar, tendo em vista a vitória ideológica do mercado e da democracia liberal sobre os ideais igualitaristas. Os direitos sociais, nesse contexto, são facilmente flexibilizados em nome do livre jogo do mercado, comprometendo a dignidade e solidariedade humanas, o que, para a racionalidade neoliberal, não significa um problema, tendo em vista que sua lógica não tem qualquer compromisso ético. As abordagens críticas da história do direito internacional, por outro lado, baseadas na necessidade de democratizá-lo, propõem assumir uma postura ética (GALINDO, 2015) e desviar seu foco para os interesses dos povos do terceiro mundo, inclusive redirecionando o foco do direito internacional do Estado para os movimentos sociais (RAJAGOPAL, 2003).

O cenário atual, tanto nacional quanto internacionalmente, evidencia a necessidade de que se reoriente o direito internacional como instrumento para efetivação da dignidade humana, e não mais para a realização de propósitos de poder dos estados soberanos (CANÇADO TRINDADE apud RAMINA, 2014) e a história crítica do direito internacional tem muito a contribuir nessa trajetória, cumprindo papel de denúncia e de questionamento do que está posto, a partir de uma abertura a narrativas desde o terceiro mundo.

A história do direito internacional possui, portanto, dimensão prática, na qual a crítica cumpre papel fundamental, permitindo que, por meio de vozes historicamente silenciadas e atualmente marginalizadas pelo autodenominado centro hegemônico, se apontem caminhos que podem disputar espaços na organização jurídica internacional e, dessa forma, espraiar cada vez mais ideais igualitários e democráticos em nível global, na busca por sepultar qualquer resquício de colonialidade.

\section{Considerações finais}

O professor doutor André Roberto Martin, por ocasião de palestra no Simpósio Internacional Pensar e Repensar a América Latina, que ocorreu em novembro de 2014 sob organização do Programa de Pós-graduação Integração da América Latina da Universidade de 
São Paulo², rememorou que a simples menção a "América Latina" trazia consigo uma conotação de certa subversão, que coordenava reflexão teórica com ação política. Lamentou, entretanto, que isso tenha se rompido ao longo do tempo.

O que se observou, por exemplo, nas chamadas "jornadas de junho de 2013" no Brasil foi um grande ímpeto de manifestação popular sem uma análise prévia e teórica dessa ação política, que acarretou desastrosamente em um golpe travestido juridicamente de impeachment, bem assim impulsionou a vitória de Jair Messias Bolsonaro ao mais alto cargo do Poder Executivo no país, com um discurso bastante e escancaradamente guinado e subordinado ao imperialismo norte-americano.

Sobressai do contexto brasileiro, inserto geopoliticamente na América Latina, a necessidade de retomar teorias e afinar reflexões que possam servir de embasamento para uma ação política prática, caso se almeje extirpar imperialismos da região e se queira transformar concretamente a realidade latino-americana, hipótese em que, como propõe Quijano, se deve dar em um mesmo movimento histórico.

A heterogeneidade e a complexidade típica e inerente a qualquer tempo desafia abordagens multidisciplinares, especialmente na hipótese de se assumir postura crítica em relação à análise que se pretende construir. Os debates pós e decoloniais, conjugados com seus reflexos nos estudos da denominada virada historiográfica no direito internacional, em especial na América Latina, carregam sentido não meramente acadêmico, mas podem ensejar resultado político material, especialmente por meio de disputas no âmbito de organizações internacionais que, por consequência, podem impactar positivamente em nível mundial.

Buscou-se, com o presente estudo, demonstrar que se produz conhecimento válido e igualmente legítimo em países do "terceiro-mundo", e as viradas decolonial e historiográfica no direito internacional representam importante passo no caminho de rompimento em relação à ideia de que existe um único sistema possível e um único valor democrático mundial. É nítido o processo em marcha no qual uma única potência tem a pretensão de impor seus valores liberais e de dar a última palavra para que se preservem referidos valores. Ainda que os países da América Latina guardem peculiaridades próprias, têm em comum que sofrem a mesma pressão de países centrais que não querem deixar que suas economias cresçam autonomamente.

$\overline{2}$ o inteiro teor de sua intervenção pode ser acessado pela URL:
<https://www.youtube.com/watch? $=88 q$ aMPDMvVs>. 
De um lado, existe uma estratégia bastante clara de dominação monopolar e, de outro lado, até então, não se verifica uma estratégia articulada daqueles que defendem um mundo multipolar. A construção de uma identidade e de um sentimento latino-americano, inclusive por meio de reflexões decoloniais no direito internacional, pode contribuir para frear a dominação do projeto neoliberal nessa região, enfrentando de forma mais autônoma e coordenada as ameaças do projeto que se pretende hegemônico, tanto em nível epistêmico quanto filosófico e científico.

A atitude crítica está sujeita a constantes ajustes e modificações, e esse, segundo GALINDO, deve ser o esforço do qual a história do direito internacional não pode abrir mão: "estar aberta a revisão, todo o instante, ainda que isso nos traga instabilidade" (GALINDO, 2015).

\section{Referências bibliográficas}

BALLESTRIN, Luciana. América Latina e o giro decolonial. Revista Brasileira de Ciência Política, Brasília, n. 11, p. 89-117, maio-ago. 2013.

BITTENCOURT, Naiara Andreoli; MASO, Tchenna Fernandes. Reflexões descoloniais: aportes da inflexão latino-americana de Aníbal Quijano. Seminário América Latina: Cultura, História e Política. Uberlândia, 2015. Disponível em: <http://seminarioamericalatina.com.br/wp-content/uploads/2015/07/Reflex\%C3\%B5esdescoloniais-aportes-da-inflex\%C3\%A3o-latino-americana-de-An\%C3\%ADbal-QuijanoNaiara-Andreoli-Bittencourt-e-Tchenna-Fernandes-Maso.pdf>. Acesso em 21 set. 2019. CHIMNI, B.S. Marxism and international law: a contemporary analysis. Economic and political weekly, v. 34, n. 6, p. 337-349, 1999.

. An outline of a marxista course on public international law. Leiden jornal of international law, v. 17, p. 1-30, 2004.

DUSSEL, Enrique. 1992 o encobrimento do outro: a origem do mito da modernidade. Jaime

A. Clasen (Trad.). Petrópolis: Vozes, 1993.

ESLAVA, Luis; OBREGÓN, Liliana; URUEÑA, René. Imperialismo(s) y derecho(s) internacional(es): ayer y hoy. In: ANGHIE, Antony; KOSKENNIEMI, Martii; ORFORD, Anne. Imperialismo y derecho internacional: historia y legado. Jorge González Jácome (Trad.). Bogotá: Siglo del Hombre Editores, 2016.

FONSECA, Ricardo Marcelo. Introdução teórica à história do direito. Curitiba: Juruá, 2011.

GALINDO, George Rodrigo Bandeira. Para que serve a história do direito internacional? Revista de Direito Internacional, Brasília, v. 12, n. 1, p. 338-354, 2015. 
GANDHI, Leela. Postcolonial theory: a critical introduction. Nova York: Columbia University Press, 1988.

GATHII, James Thuo. The agenda of Third World Approaches to International Law (TWAIL). In: Jeffrey Dunoff and Mark Pollack (eds.). International Legal Theory: foundations and frontiers. Cambridge University Press, 2019. Disponível em: $<$ https://ssrn.com/abstract=3304767>. Acesso em 22 set. 2019.

GORDON, R. W. The struggle over the past. Cleveland State Law Review, Cleveland, v. 44, n. 2, p. 123-143, 1996.

KOSKENNIEMI, Martii. The gentle civilizer of nations: the rise and fall of international law 1870-1960. Cambridge: Cambridge University Press, 2001.

Histories of international lae: dealing with eurocentrism, Rechtsgeschichte, $\mathrm{n}$. 19, pp. 152-176, 2011.

Histories of international law: significance and problems for a critical view. Temple international and comparative law jornal, v. 27, 2013.

LANDER, Edgardo. Ciencias sociales: saberes coloniales y eurocêntrico. In: LANDER, Edgardo. (Org). A colonialidade do saber: eurocentrismo e ciências sociais. 1a. ed. Buenos Aires: Consejo Latinoamericano de Ciências Soociales - CLACSO, 2005.

MANTELLI, Gabriel Antonio Silveira; ALMEIDA, Julia de Moraes. Entre o pós-colonial, o decolonial e o socioambiental: leituras sociojurídicas na América Latina. Sociedade em debate. (Pelotas), v. 25, n. 2, p. 11-23, maio/ago. 2019. ISSN: 2317-0204

MIGNOLO, Walter. Histórias locais, projetos globais: colonialidade, saberes subalternos e pensamento liminar. Belo Horizonte: Universidade Federal de Minas Gerais, 2003.

MUTUA, Makau. What is TWAIL? American Society of International Law, Proceeding of the 94th Annual Meeting, p. 31-39, 2000.

QUIJANO, Aníbal. Colonialidad y modernidad/racionalidad. In: BONILLA, Heraclio (Org.). Los conquistados. 1492 y la población indígena de las Américas. Ecuador: Libri Mundi, Tercer Mundo Editores, 1992.

Colonialidade do poder, eurocentrismo e América Latina. In: LANDER, Edgardo (org). A colonialidade do saber: eurocentrismo e ciências sociais - perspectivas latino-americanas. Tradução De Júlio César Casarin Barroso Silva. Buenos Aires: CLACSO, 2005. p. 227-278.

. Os fantasmas da América Latina. In: NOVAES, Adauto (org.). Oito visões da América Latina. São Paulo: SENAC, 2006, p. 49-85. 
RAJAGOPAL, Balakrishnan. International law from below: development, social movements and Third World Resistance. Cambridge: Cambridge University Press, 2003.

RAMINA, Larissa. O direito e a ordem internacional no século XXI: complexidades e reflexões na contemporaneidade. In: RAMINA, Larissa; FRIEDRICH, Tatyana Scheila. (coord.). Direitos humanos, evolução, complexidade e paradoxos. vol. 1. Curitiba: Juruá, 2014.

RIVEIRA, Silvia Cuisicanqui. Ch'ixinakax utxiwa: una reflexión sobre prácticas y discursos descolonizadores. 1. ed. Buenos Aires: Tinta Aimón, 2010.

SANTOS, Boaventura de Sousa. Entre Próspero e Caliban: colonialismo, pós-colonialismo e interidentidade. Novos Estudos CEBRAP, São Paulo, n. 66, p. 23-52, jul. 2003.

. Para além do pensamento abissal: das linhas globais a uma ecologia de saberes.

Revista crítica de ciências sociais, 78, out. 2007. 